\title{
Diffusion and Regionalization
}

\section{in Membranes of Maturing Ram Spermatozoa}

\author{
DAVID E. WOLF and JOSEF K. VOGLMAYR \\ Endocrine Reproductive Biology Group, Worcester Foundation for Experimental Biology, \\ Shrewsbury, Massachusetts 01545
}

\begin{abstract}
An essential feature of the "fluid mosaic model" (Singer, S. J., and G. L. Nicolson, 1972, Science (Wash. DC)., 175:720-731) of the cell plasma membrane is the ability of membrane lipids and proteins to diffuse laterally in the plane of the membrane. Mammalian sperm are capable of overcoming free random diffusion and restricting specific membrane components, both lipid and protein, to defined regions of the sperm's surface. The patterns of these regionalizations evolve with the processes of sperm differentiation: spermatogenesis, epididymal maturation, and capacitation.

We have used the technique of fluorescence recovery after photobleaching to measure the diffusion of the lipid analogue $1,1^{\prime}$-dihexadecyl 3,3,3',3'-tetramethylindocarbocyanine perchlorate $\left(C_{16}\right.$ dil) on the different morphological regions of testicular and ejaculated ram spermatozoa. We have found: (a) that the major morphologically distinct regions (head, midpiece, and tail) of the plasma membrane of both testicular and ejaculated spermatozoa are also physically distinct as measured by $\mathrm{C}_{16}$ dil diffusibility; (b) that despite regional differences in diffusibility there is exchange of this lipid analogue by lateral diffusion between the major morphological regions of the plasma membrane; and (c) that epididymal maturation results in changes in $\mathrm{C}_{16}$ dil diffusibility in the different regions of the sperm plasma membrane. In particular, the plasma membranes of the anterior and posterior heads become physically distinct.
\end{abstract}

Since the experiments of Frye and Edidin (16) demonstrating the ability of surface antigens to intermix upon heterokaryon fusion, it has been clear that, in general, the components of the cell's plasma membrane are free to diffuse within the plane of the membrane. The development of techniques such as fluorescence recovery after photobleaching (FPR) ${ }^{1}$ has made feasible measurements of the rates of diffusion for membrane lipids and proteins in a wide variety of systems (for reviews see references $7,10,32$ ). Diffusion is a random process (11). However, during a number of important processes of cellular differentiation, such as sperm maturation and capacitation (4), early embryogenesis $(21,52-55)$, erythropoesis (36), tight junction formation in epithelia $(26,45)$, and myotube development (2), cells demonstrate their ability to

\footnotetext{
${ }^{1}$ Abbreviations used in this paper: $\mathrm{C}_{16}$ dil, 1,1'-dihexadecyl 3,3,3',3'tetramethylindocarbocyanine perchlorate; $D$, diffusion coefficient; FPR, fluorescence recovery after photobleaching; $\% R$, percent recovery.
}

overcome the randomizing effect of diffusion and to localize certain membrane components to specific regions of the cell surface. The ubiquity of surface regionalizations during cellular differentiation suggests a close relationship between these two phenomena and demonstrates the need to understand how cells restrain the free diffusion of their surface components if one hopes to understand the processes of differentiation.

A clear example of surface component regionalization and its relationship to differentiation is exhibited by mammalian sperm. Sperm localize a number of surface componentsantigens $(12,22,23,27,37,38,47)$, enzymes (for review see reference 22 ), lectin receptors $(22,27-29)$, charged lipids (4, $14)$, and cholesterol $(4,14)$ - to specific surface regions. Some of these patterns of regionalization are transformed during the differentiative processes of epididymal maturation (29) in the male tract and capacitation $(4,30)$ in the female tract, which relate to the important physiological changes of the 
acquisition of sperm motility, the acrosome reaction, and fertilization competence.

Recent experiments indicate that the diffusion of membrane lipids and proteins can be controlled by different factors $(46,55)$. Thus, the issue of how the sperm localizes its surface components must be addressed separately for lipids and proteins. In this paper we consider control of regionalization of lipids on testicular and ejaculated ram sperm. Using FPR and the lipid analogue 1,1'-dihexadecyl-3,3,3'3'-tetramethylindocarbocyanine perchlorate $\left(\mathrm{C}_{16} \mathrm{diI}\right)(42)$, we have shown that: (a) there are regional differences in lipid diffusibility in the plasma membrane of ram sperm; $(b)$ lipids are free to exchange in the plane of the membrane between the major surface regions; and $(c)$ lipid diffusibility changes with epididymal maturation.

\section{MATERIALS AND METHODS}

Sheep: Sperm used in these experiments were collected as described below from Shropshire rams aged 4-6 yr. These animals were maintained in a controlled environment ( $12 \mathrm{~h}$ of light/day at $15^{\circ} \mathrm{C}$ ).

Sperm: Ejaculated spermatozoa and seminal plasma were obtained by electrical stimulation using the bipolar electrode described by Blackshaw (6). To avoid sudden temperature changes, the semen was collected and stored in a receptacle maintained at $34^{\circ} \mathrm{C}$. Epididymal sperm were collected as described by Dacheux and Voglmayr (8). Testicular spermatozoa and rete testis fluid were collected through a catheter inserted into the rete testis as described by Voglmayr et al. (50). The free end of the catheter was placed into a receptacle attached to the anterior surface of the scrotum.

Immediately after collection, sperm were washed three times in Kreb's
Ringer phosphate (KRP) containing $5 \mathrm{mM}$ glucose by centrifugation at 500 $g_{\text {max }}$. Spermatozoa can be maintained in this medium at $34^{\circ} \mathrm{C}$ for $\sim 3 \mathrm{~h}$ without significant dimunition in respiratory or glycolytic activities (49).

Labeling with Lipid Probe: Sperm were labeled with the fluorescent lipid analogue $\mathrm{C}_{16}$ diI (Molecular Probes, Eugene, OR). The carbocyanine dyes have been extensively studied and used as membrane probes, particularly for lateral diffusion measurements $(13,32,42,52,53)$. Sperm were labeled with $\mathrm{C}_{16}$ diI as follows. $5 \times 10^{6}$ sperm were added to $200 \mu \mathrm{l}$ of $\mathrm{KRP}$ plus $5 \mathrm{mM}$ glucose plus $0.4 \%$ BSA containing $4 \mu \mathrm{g} / \mathrm{ml}$ of $\mathrm{C}_{16} \mathrm{diI}$ and $0.5 \%$ ethanol and incubated for $8 \mathrm{~min}$ at $34^{\circ} \mathrm{C}$. This suspension was then layered above $2 \mathrm{ml}$ of KRP plus $5 \mathrm{mM}$ glucose plus $10 \% \mathrm{BSA}$ (in the case of ejaculated sperm, $0.2 \%$ $\mathrm{NaN}_{3}$ was added to this medium to immobilize them during observation). In the absence of $\mathrm{NaN}_{3}$, these sperm remained motile after labeling in a conical centrifuge tube and spinning for 3-5 min at $500 \mathrm{~g}$ to remove free dye. Sperm were then observed or measured between an acid-washed slide and coverslip.

FPR: The technique of FPR has been described in detail elsewhere $(1,25$, 51). FPR provides two measures of lateral diffusion in the plane of the membrane: $(a)$ the fraction of the component that is free to diffuse $(\% R)$, and $(b)$ the diffusion coefficient $(D)$ of that fraction. Our instrument is similar to published designs $(25,51)$ and the specifics of our instrument have been described elsewhere (54). The beam exp $(-2)$ radius was determined (39) to be $(0.63 \pm 0.10) \mu \mathrm{m}$. Bleaching times were $\sim 5 \mathrm{~ms}$ at $\sim 10 \mathrm{~mW}$ at $514.5 \mathrm{~nm}$. Monitoring intensities were $\sim 1 \mu \mathrm{W}$. The counting interval was $30 \mathrm{~ms}$. Data were fitted by nonlinear least-squares programs after Bevington (5), according to algorithms described by Barisas and Leuther (3) and Wolf and Edidin (51). Data were corrected for sperm geometry. The one- and two-dimensional solutions appropriate to the tail and head, respectively, can be found in the literature (1, 24). A solution appropriate for the midpiece was developed using standard procedures and assuming a Gaussian beam and diffusion on a cylinder. Details will be published elsewhere (D. E. Wolf, manuscript in preparation).

Intensified Video Microscopy: Intensified video micrographs were made using a Dage MTI SIT camera on a Leitz Dialux microscope (E. Leitz, Inc., Rockleigh, NJ) using an N2.1 filter system and an attenuated mercury
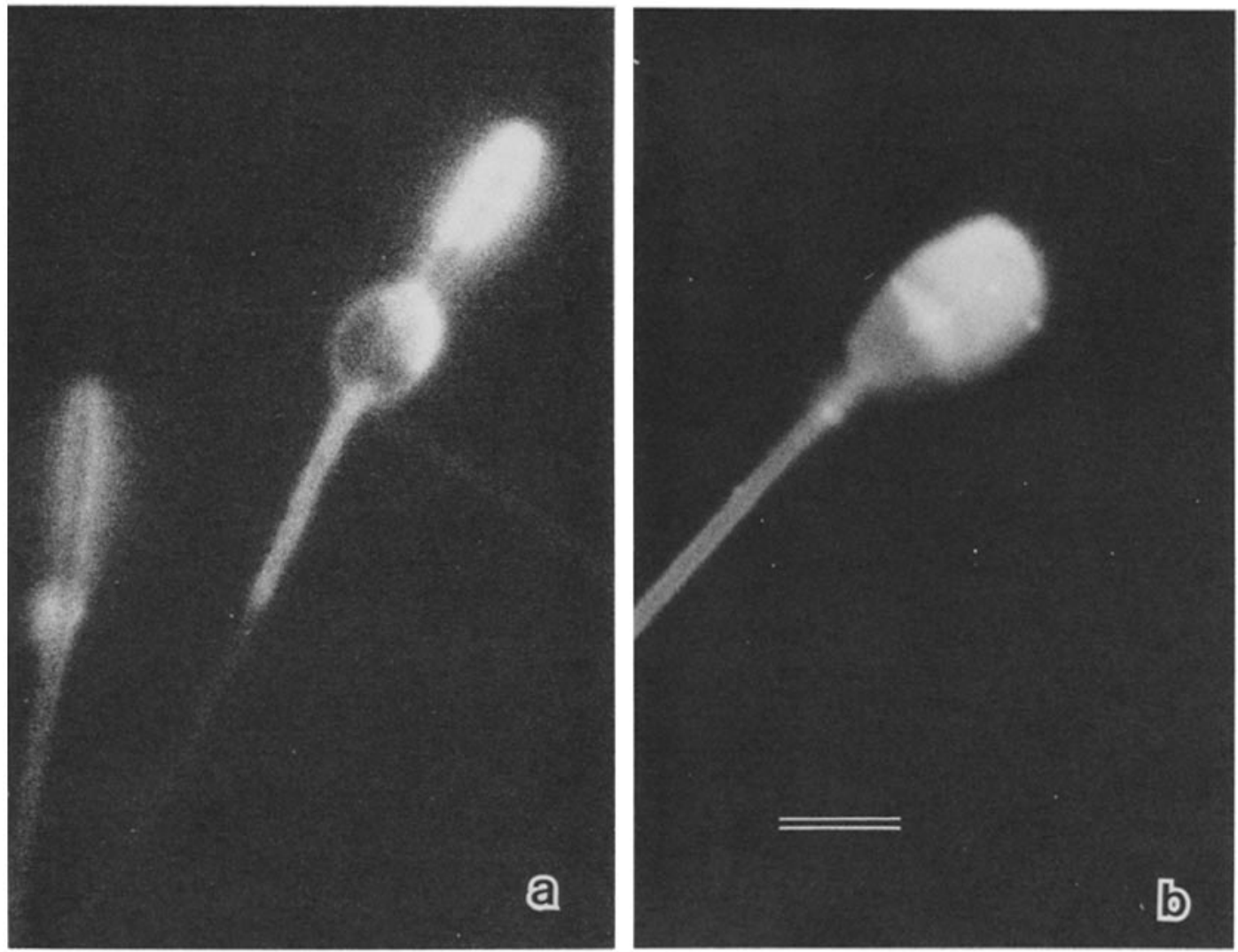

Figure 1 High power fluorescence photomicrographs of ram sperm labeled with $\mathrm{C}_{16}$ dil. (a) Two testicular sperm in optical section. Sperm on left shows "ring" staining of head with no evidence of staining of nuclear or acrosomal membrane, which should appear as a cross-bridge between the plasma membrane. Anterior head is stained more intensely than the posterior in both sperm. Sperm on right has abnormally swollen cytoplasmic droplet which is "ring stained." (b) Ejaculated sperm. The anterior head is more highly stained than the posterior head. The midpiece stains as two parallel lines (just visible here) with no cross banding. Bar, $5 \mu \mathrm{m} . \times 2,800$. 
lamp. Video records were made either by recording on a Panasonic $1 / 2$ " reel to reel video recorder or by photographing the monitor with an Olympus OM2 camera equipped with a 50-mm macro lens.

Photomicrography: Photomicrographs were made using either phase or standard epillumination of the Dialux system. All photographs were taken on Ilford XP1-400 film developed to an effective ASA of 800 .

\section{RESULTS}

Sperm that have been fluorescently labeled with $\mathrm{C}_{16}$ diI are shown in Fig. 1. Staining within morphologically distinct regions is generally homogeneous (i.e., diffuse, not patchy); however, some regions stain more intensely than others. The cytoplasmic droplet stains particularly intensely on testicular sperm. The anterior head is more intensely stained than the posterior head on both testicular and ejaculated sperm. This polarity of staining is more pronounced in ejaculated sperm, as demonstrated by comparison of fluorescence intensity between these two regions (Fig. 1). Differences in curvature between head, droplet, midpiece, and tail make direct comparisons of interregional differences in fluorescence intensity difficult. The cytoplasmic droplet is clearly "ring" stained, as is the midpiece. No banding of the midpiece is observed. Sperm that are oriented so that they can be optically sectioned laterally show "ring" staining of the head with no staining of either the acrosomal or nuclear membranes.

As discussed above, the lack of midpiece banding suggests that stain on the midpiece is confined to the plasma membrane. As a further test, $\mathrm{C}_{16}$ dil-labeled sperm (Fig. 2, $A$ and $B$ ) were mildly sonicated as described by Voglmayr et al. (48) to remove the plasma membrane. As shown in Fig. 2, $C$ and
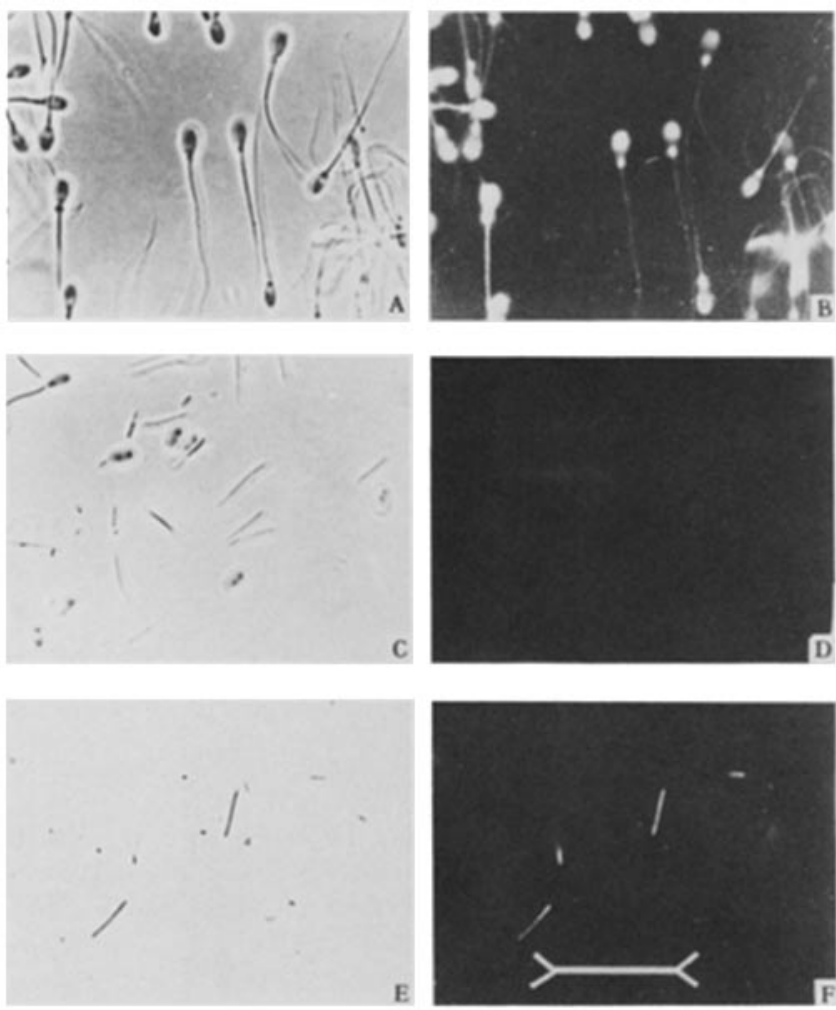

FIGURE 2 Sperm labeled with $\mathrm{C}_{16} \mathrm{dil}$; $(A)$ phase contrast, $(B)$ fluorescence. Sperm were then mildly sonicated to remove plasma membrane, $(C)$ phase contrast, $(D)$ fluorescence, to confirm presence of intact mitochondria. Sperm were then labeled with rhodamine 123; $(E)$ phase contrast, $(F)$ fluorescence. See text for experimental details. Bar, $20 \mu \mathrm{m}$. $\times 650$.

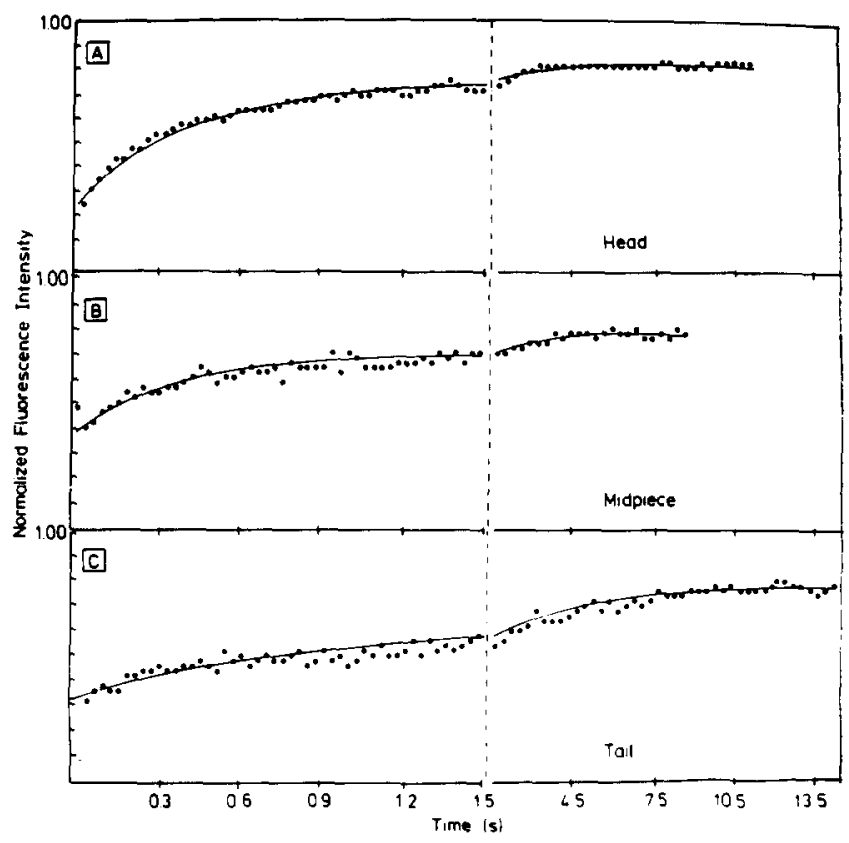

FIGURE 3 FPR recovery curves from the head $(A)$, midpiece $(B)$, and tail $(C)$ of a testicular ram sperm labeled with $C_{16}$ dil. Data are normalized so that the prebleach value is 10 . Bleach time is $4 \mathrm{~ms}$. Time between data points is $30 \mathrm{~ms}$ before the dashed vertical line, $300 \mathrm{~ms}$ after it. Dots represent data points; solid line is nonlinear least squares computer fit to the data.

$D$, all of the fluorescence is removed. These sonication conditions have been shown by electron microscopy to leave the mitochondrial membranes intact (48). To confirm this, sonicated sperm were subsequently exposed to the vital mitochondrial stain rhodamine 123 (19). As seen in Fig. 2, $E$ and $F$, the stain is intense, which indicates intact viable mitochondria.

Recently, we have been able to demonstrate that all of the $\mathrm{C}_{16} \mathrm{dil}$ is accessible to membrane-impermeable quenching agents. Thus, not only is all of the $\mathrm{C}_{16}$ diI in the plasma membrane, but it is all in the outer leaflet (D. E. Wolf, manuscript in preparation).

To rule out binding of $\mathrm{C}_{16}$ diI to surface coat proteins or BSA adhering to the cell surface, labeled sperm were treated with pronase or trypsin under conditions established by Voglmayr et al. (50) to remove coat proteins. No reduction in fluorescence intensity was observed.

The lateral diffusion of $\mathrm{C}_{16}$ diI was measured on the anterior and posterior head, the midpiece, and tail of testicular and ejaculated sperm. FPR recovery curves from a typical experiment measuring recovery on the head, midpiece, and tail of a testicular sperm are shown below in Fig. 3. As discussed above, differences in these recovery curves reflect both differences in diffusion and differences in sperm geometry. Analyzed data that have been corrected for geometric effects are summarized below in Tables I and II. Mean diffusion coefficients ranged from 0.30 to $0.93 \times 10^{-8} \mathrm{~cm}^{2} / \mathrm{s}$ and $\% R$ from 44 to 78 . In both testicular and ejaculated, sperm $D$ was largest and $\% R$ was smallest on the midpiece. $D$ and $\% R$ values were compared between regions and for the same region on testicular vs. ejaculated sperm (using Student's $t$ test). The results of these comparisons are summarized below in Figs. 4 and 5. One can ask whether the sperm's plasma membrane is physically different (as measured by $\mathrm{C}_{16}$ dil dif- 
TABLE I

Diffusion Coefficient*

\begin{tabular}{|c|c|c|c|c|c|}
\hline & \multicolumn{3}{|c|}{ Head ${ }^{*}$} & \multirow[b]{2}{*}{ Midpiece } & \multirow[b]{2}{*}{ Tail } \\
\hline & Anterior & Posterior & Total & & \\
\hline Testicular & $\begin{array}{c}0.37 \pm 0.06 \\
(32)\end{array}$ & $\begin{array}{c}0.35 \pm 0.05 \\
(33)\end{array}$ & $\begin{array}{c}0.46 \pm 0.03 \\
\cdot(91)\end{array}$ & $\begin{array}{c}0.63 \pm 0.03 \\
(54)\end{array}$ & $\begin{array}{c}0.33 \pm 0.02 \\
(54)\end{array}$ \\
\hline Ejaculated & $\begin{array}{c}0.63 \pm 0.06 \\
(24)\end{array}$ & $\begin{array}{c}0.59 \pm 0.06 \\
(24)\end{array}$ & $\begin{array}{c}0.70 \pm 0.05 \\
(87)\end{array}$ & $\begin{array}{c}0.93 \pm 0.20 \\
(45)\end{array}$ & $\begin{array}{c}0.48 \pm 0.07 \\
(25)\end{array}$ \\
\hline
\end{tabular}

* $D$ is given as mean $\pm S E M \times 10^{8} \mathrm{~cm}^{2} / \mathrm{s}$. The number of measurements is given below each value in parentheses.

* Measurements on the anterior and posterior head represent a subset of all head measurements and thus the anterior and posterior head values should only be compared with each other.

TABLE II

Percent Recovery *

\begin{tabular}{lccccc}
\hline & \multicolumn{3}{c}{ Head $^{*}$} & & Mid- \\
& Anterior & Posterior & Total & piece & Tail \\
\cline { 2 - 4 } Testicular & $65 \pm 2$ & $69 \pm 2$ & $69 \pm 1$ & $52 \pm 1$ & $78 \pm 1$ \\
& $(32)$ & $(33)$ & $(91)$ & $(55)$ & $(54)$ \\
Ejaculated & $58 \pm 3$ & $71 \pm 2$ & $63 \pm 2$ & $44 \pm 3$ & $58 \pm 4$ \\
& $(24)$ & $(24)$ & $(87)$ & $(47)$ & $(25)$
\end{tabular}

$* \% R$ is given as mean \pm SEM. The number of measurements is given below each value in parentheses.

- Measurements on the anterior and posterior head represent a subset of all head measurements and thus the anterior and posterior head values should only be compared with each other.

fusion) over the major morphologically distinct regions of the sperm (head, midpiece, and tail). As seen in Figs. 4 and 5, significant differences between all regions were observed in either $D, \% R$, or both parameters on both testicular and ejaculated sperm. $D$ was found to be the same on the anterior and posterior heads of both testicular and ejaculated sperm. $\% R$ was found to be the same on the anterior and posterior heads of testicular sperm, but greater on the posterior than the anterior head of ejaculated sperm. This latter fact reflects a decrease in $\% R$ in the anterior head, resulting from epididymal maturation accompanied by no change in $\% R$ for the posterior head. Maturation resulted in an increase in $D$ for all regions compared except the midpiece, and a decrease in $\% R$ for all regions compared, except, as noted above, for the posterior head.

A further differentiation that develops between the anterior and posterior head is an enhancement of the ratio of anterior to posterior fluorescence. This can be obtained from the prebleach values of fluorescence. This ratio increases from $1.28 \pm 0.07$ for testicular sperm to $1.9 \pm 0.2$ for ejaculated sperm. Comparisons between other regions are difficult to make accurately since differences in geometry and positioning affect absolute values of fluorescence intensity.

An obvious distinguishing feature between testicular and ejaculated sperm is the presence of the cytoplasmic droplet on testicular sperm. On sperm collected from the appropriate region of the epididymis, the cytoplasmic droplet divides the midpiece into a proximal half and a distal half. To determine if this results in further membrane regionalization, we measured $\mathrm{C}_{16}$ dil diffusion on the proximal and distal midpieces of such sperm. On the proximal midpiece we found $D=0.84$ $\pm 0.06 \times 10^{-8} \mathrm{~cm}^{2} / \mathrm{s}$ with $\% R=65 \pm 2$. On the distal midpiece we found $D=0.78 \pm 0.07 \times 10^{-8} \mathrm{~cm}^{2} / \mathrm{s}$ with $\% R$

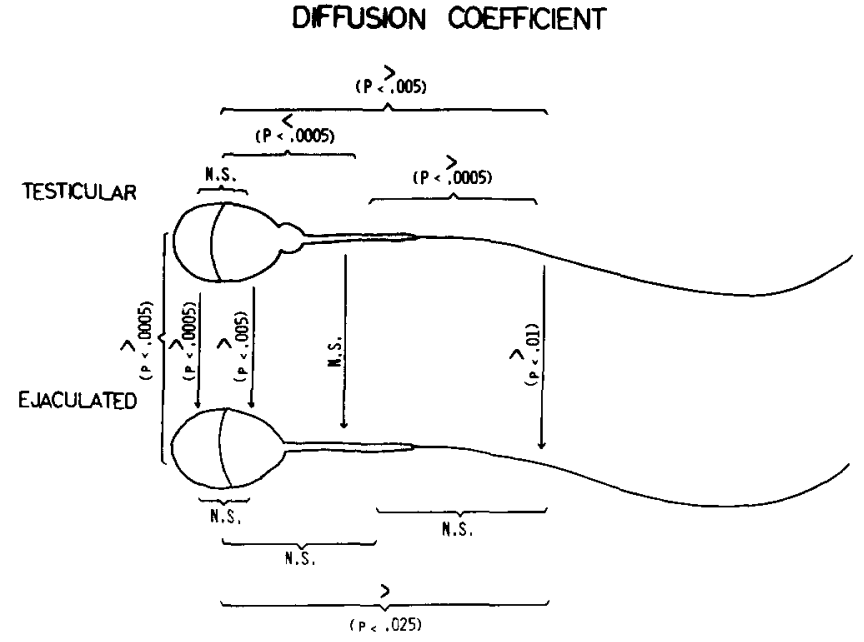

Figure 4 Significance of observed differences in diffusion coefficient. Brackets and arrows indicate regions compared. $P$ Values are given in parentheses. Direction of difference is indicated by $>$ or $<$ above $P$ value. N.S., not significant.

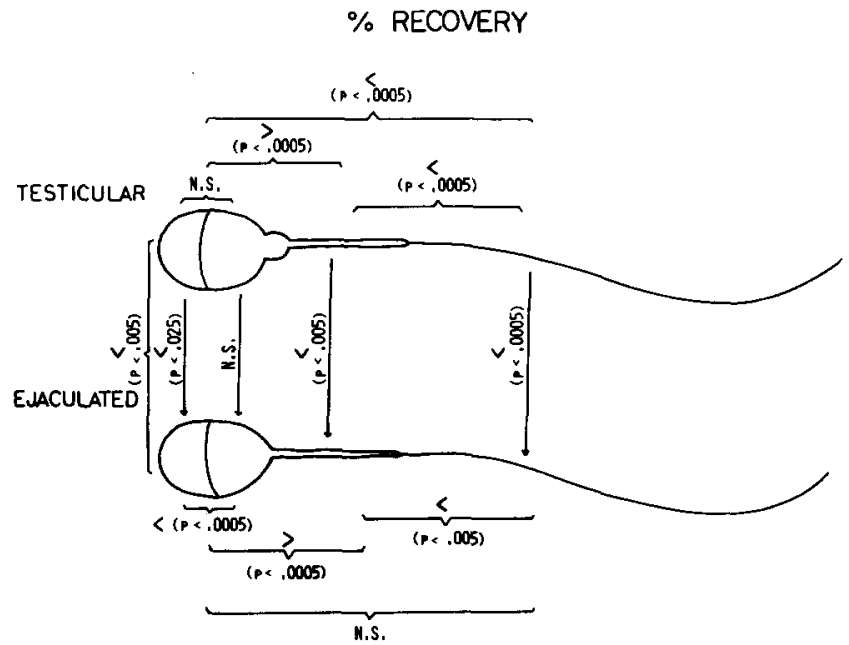

FIGURE 5 Significance of observed differences in $\% R$. Brackets and arrows indicate regions compared. $P$ values are given in parentheses. Direction of difference is indicated by $>$ or $<$ above $P$ value. N.S., not significant.

$62 \pm 2$. Thus, no regionalization of the midpiece, as defined by $\mathrm{C}_{16}$ dil diffusion, was observed.

The particularly low values of $\% R$ obtained on the midpieces suggested to us the possibility that diffusion might be permitted around the midpiece, but not along it, being re- 

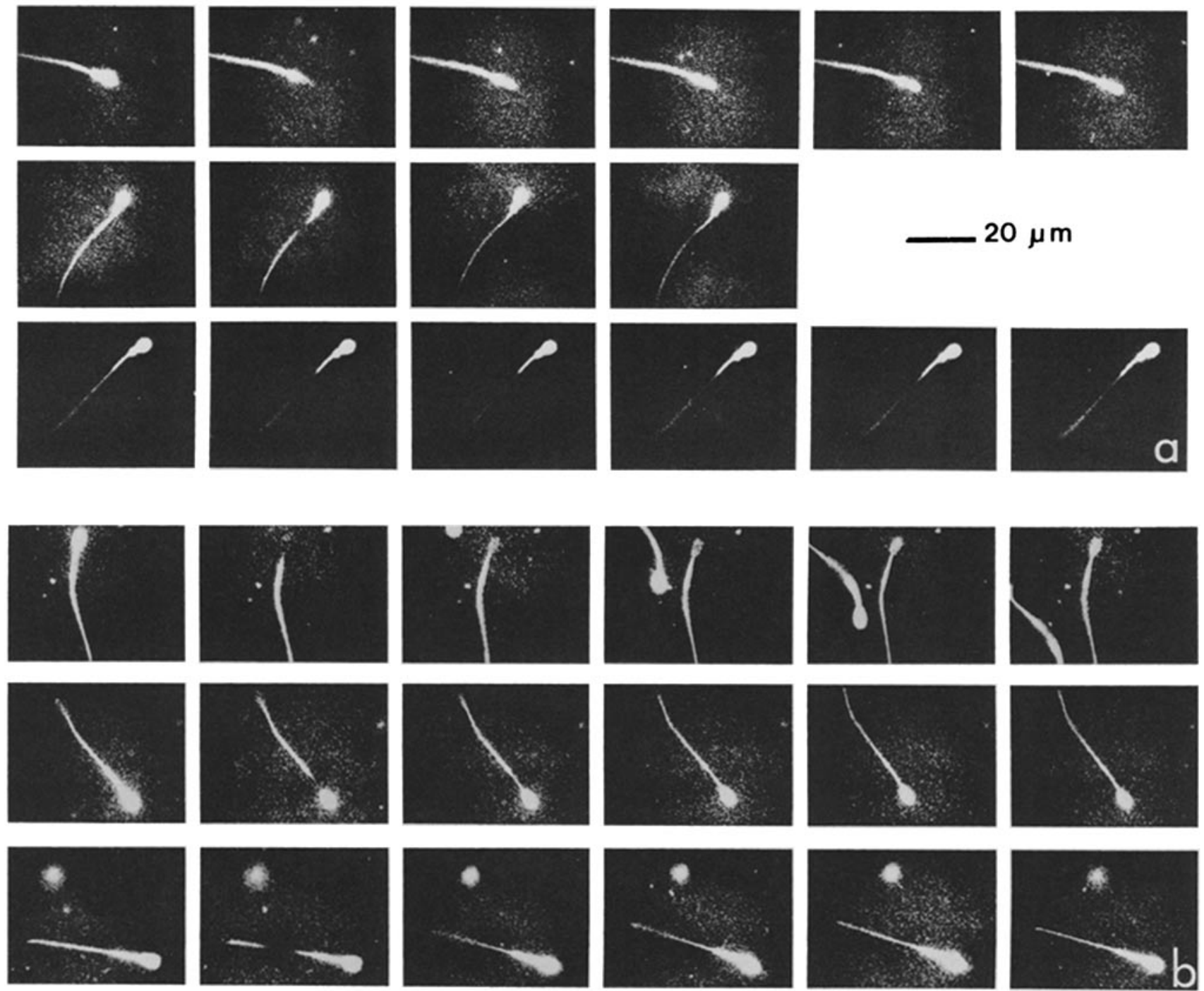

FIGURE 6 Intensified video images of fluorescence of ram sperm labeled with $\mathrm{C}_{16}$ dil. Gain was set to give a saturating image. The laser beam was positioned on a region of the sperm and all of the fluorescence in that region was bleached by an extended laser flash of $3 \mathrm{~s}$. Recovery of fluorescence was then followed in (a) testicular sperm and (b) ejaculated sperm. The first column in each series is prebleach. The second column is immediately postbleach, and each subsequent column is $60 \mathrm{~s}$ after the previous one, except the middle group for ejaculated sperm, where the third photograph in the series was taken $15 \mathrm{~s}$ after bleach. $\times 500$.

stricted perhaps by the bands of intramembranous particles observed on sperm midpieces (15). A related question is whether lipid probe is free to exchange between the different regions of the continuous plasma membrane. To address these questions, labeled sperm were observed by using attenuated mercury lamp illumination (100-W lamp attenuated $10^{3}$-fold) with the intensified video system. Such sperm are shown as the first image in each series in Fig. 6. The gain setting of the video camera was set so that the initial fluorescence was saturating. (This condition obviates initial regional intensity differences.) The laser beam was positioned on either the head (top series), midpiece (middle series), or tail (bottom series) of the sperm. The laser intensity was held at bleaching level for $\sim 3 \mathrm{~s}$ so as to bleach a large area adjacent to the boundary or boundaries between regions of the sperm surface. After bleach the sperm was immediately observed under the mercury lamp illumination (second frame of each series) and the recovery was followed. Subsequent frames were taken at 1min intervals, except for the third frame of the midpiece series for ejaculated sperm, which was taken $15 \mathrm{~s}$ after bleach (so as to capture the rapid recovery caused by the relative high diffusion on the midpiece). These time series show that the lipid analogue is free to exchange in both directions between head and midpiece and midpiece and tail on both testicular and ejaculated sperm and to diffuse along the midpiece of both stages of sperm.

\section{DISCUSSION}

As discussed above, spermatozoa overcome random diffusion and localize a number of their surface components, both protein and lipid $(4,12,14,22,23,27-29,37,38,42)$, to specific regions of their membrane surfaces. The patterns of these surface regionalizations evolve during the processes of spermatogenesis (27), epididymal maturation (29), and capacitation $(4,30)$. This suggests a relationship between these membrane changes and the specialized physiological changes of acquisition of sperm motility, the acrosome reaction, and 
fertilization competence.

FPR studies on a multitude of cell types indicate that the factors that govern membrane lipid and protein diffusibility are potentially different, so that they must be considered separately. In the present study we have considered lipid regionalization and diffusibility during epididymal maturation in the ram. The lipid analogue $\mathrm{C}_{16}$ diI was chosen for these studies because it has been shown to behave as a typical lipid (for review see reference 32) and because its fluorescence properties make it particularly well suited for photobleaching studies $(32,51)$.

A further advantage of $\mathrm{C}_{16} \mathrm{diI}$ is that it is cationic. The involvement of charged lipids and specific domains in fusion events has been suggested by Portis et al. (33). The ability of mammalian sperm to localize charged lipids has been demonstrated for both the guinea pig (4) and the ram (14). It has been suggested that changes in these distributions with capacitation result in fusogenic lipid domains that permit the acrosome reaction (4). Thus, lipids may play a decisive role in the acrosome reaction. If this is so, then one would expect to find (as we have here) an alteration in the fluidity state (reflected in $D$ and $\% R$ for $\mathrm{C}_{16} \mathrm{diI}$ ) of the anterior head with sperm maturation. One would predict further alterations in the fluidity state of this region to evolve during the subsequent stages of sperm capacitation. This is presently being investigated.

There is considerable evidence for changes in overall lipid composition during maturation. Ram sperm lose between 25 and $50 \%$ of their phospholipids during epididymal transit (35). Specifically, there is a decrease in the cholesterol to phospholipid ratio (40) and a decrease in the concentrations of phosphatidyl serine, phosphatidyl ethanolamine, cardiolipin, and ethanolamine plasmologen $(35,40)$. The amount of the major phospholipid choline plasmologen remains unchanged (40). Accompanying these changes is an increase in unsaturated fatty acid chains, particularly the polyunsaturate 22:6 (40). This latter point is particularly interesting since the sperm of ruminants have high levels of plasmologen phospholipids (35-41\%) and these account for high percentages of the polyunsaturates $(9,18)$. It has been predicted that high levels of polyunsaturate plasmologens would result in a particularly fluid membrane (18). Neither our studies nor spin resonance studies (17) support this prediction. If anything, the sperm plasma membrane is less fluid than other plasma membranes $(7,10,32)$, as reflected in the relatively low $\% R$ s that we have observed. We have further demonstrated that the "fluidity" of the sperm plasma membrane differs in the morphologically distinct regions of the sperm. Thus, it is an oversimplification to speak of a bulk plasma membrane fluidity. Indeed, the high levels of choline plasmologens and polyunsaturates in these spermatozoa may be a controlling factor in the lateral phase separations that induce regionalization of membrane lipids $(20,31,34,41,44)$. It thus becomes important to take on the difficult task of determining local lipid composition. As discussed above, such studies are beginning to be carried out using in situ probes of lipid composition such as polymixin $B$ filipin (4). Fluorescent probes such as $\mathrm{C}_{16} \mathrm{diI}$ and related dyes $(21,36,42,52,53)$ should also be useful in this regard. They have the further advantage, as demonstrated here, of providing direct information about the physical state of the probe's environment.

There are a number of biological mechanisms by which a cell can maintain a regionalized distribution of a surface component in its plasma membrane. In thermodynamic terms, however, the cell must either create a miscibility (chemical potential) gradient for that component within the plasma membrane or else prevent exchange by lateral diffusion between regions. This latter mechanism could be effected either by immobilization of that component within a region or by establishing a barrier to diffusion between regions. We have shown that the lipid analogue $\mathrm{C}_{16}$ dil is capable of exchanging in all directions between the major morphological regions of both testicular and ejaculated ram sperm. Thus, an absolute barrier to interregional lipid diffusion does not appear to exist. In these exchange experiments we could not determine if there is complete exchange of material. Since there are large nondiffusing fractions, immobilization may still play a role in regionalization. Miscibility differences must also exist, however, since on ejaculated sperm the difference in mobile fraction between the anterior and posterior head is insufficient to account for the observed concentration gradient. As in the case of diffusion rates and diffusing fractions, differences in the affinity of a probe for one region or another can result from interactions of the probe with lipids and proteins within the membrane. The establishment of a nonhomogeneous distribution of a single membrane component by whatever mechanism will result in a nonhomogeneous distribution in any other components that interact with the first, simply by virtue of the interactions. One can envision a cascade of regionalizations developing from a single regionalization.

The most obvious physiological change in ram spermatozoa during epididymal transit is the development of motility. One might predict that the development of flagellar motion would require a fluidization of the sperm tail plasma membrane. Our measurements demonstrate that this is not the case. While this may at first be surprising, it must be remembered that, as is the case for a flexible metal rod, elasticity rather than fluidity is required for flagellar motion.

In conclusion, we have found that:

(a) There are differences between the major morphological regions in the diffusibility within the plasma membrane of the lipid analogue $C_{16}$ diI on testicular and ejaculated ram sperm. Thus, the continuous sperm plasma membrane cannot be considered as having a single "fluidity." The "fluidity" and lipid composition of the morphologically distinct regions must be considered separately.

(b) Despite regional differences in diffusibility, there is exchange of this lipid analogue by lateral diffusion between major morphological regions of the plasma membrane. Thus, there is not an absolute barrier to lipid exchange between these regions.

(c) There are changes in lipid probe diffusibility with epididymal maturation. In particular, a distinction develops between the anterior and posterior head. Presumably, this distinction reflects the initiation of membrane regionalization essential to the acrosome reaction.

We wish to acknowledge the assistance of Ms. Stephanie Hagopian and Mr. Rick Sawyer in performing these experiments.

This work was supported in part by National Institutes of Health grants HD 09356 (to J. K. Voglmayr), HD 15272 (to J. K. Voglmayr), and HD 17377 (to D. E. Wolf), by grant RR05528 from Biomedical Research Support Grant, and by a private grant from the A. W. Mellon Foundation to the Worcester Foundation.

A preliminary report of this research was presented at the 22nd Annual Meeting of the American Society of Cell Biologists. 
Received for publication 20 July 1983, and in revised form 12 January 1984.

\section{REFERENCES}

1. Axelrod, D., D. E. Koppel, J. Schlessinger, E. Elson, and W. W. Webb. 1976. Mobility measurement by analysis of fluorescence photobleaching recovery kinetics. Biophys. 16:1055-1069

2. Axelrod, D., P. Ravdin, D. E. Koppel, J. Schlessinger, W. W. Webb, E. L. Elson, and T. R. Podleski. 1976. Lateral motion of fluorescently labeled acetylcholine receptors in membranes of developing muscle fibers. Proc. Natl. Acad. Sci. USA 73:4594-4598.

3. Barisas, B. G., and M. D. Leuther. 1979. Fluorescence photobleaching recovery measurements of protein absolute diffusion constants. Biophys. Chem. 10:221-229.

4. Bearer, E. L., and D. S. Friend. 1982. Modifications of anionic lipid domains preceding membrane fusion in guinea pig sperm. J. Cell Biol. 92:604-615.

5. Bevington, P. R. 1969. Data Reduction and Error Analysis for the Physical Sciences. McGraw-Hill, Inc., New York. 336 pp.

6. Blackshaw, A. W. 1954. A bipolar electrode for the production of ejaculation in sheep. Aust. Vet. J. 30:249-250.

7. Cherry, R. 1979. Rotational and lateral diffusion of membrane proteins. Biochim Biophys. Acta. 559:289-327.

8. Dacheux, J. L., and J. Vogimayr. 1983. Sequence of specific cell surface differentiation and its relationship to exogenous fluid proteins in the ram epididymis. Biol. Reprod. 29:1033-1046.

9. Darin-Bennett, A., A. Poulos, and I. G. White. 1976. Fatty acid composition of major phosphoglycerides of ram and human spermatozoa. Andrologia. 8:37-45.

10. Edidin, M. 1981 . Molecular motions and membrane organization and function. In New Comprehensive Biochemistry. J. B. Finean and R. H. Michell, editors. Elsevier/North Holland Biomedical Press, Amsterdam. 1:37-76.

11. Einstein, A. 1905. On the movement of small particles in a stationary liquid demanded by the molecular theory of heat. Ann. Phys. (Leipzig). 17:549-554.

12. Erickson, R. P. 1977. Differentiation and other alioantigens of spermatozoa. In Immunobiology of Gametes. M. Edidin and M. M. Johnson, editors. Cambridge University Press, Cambridge, England. 85-114.

13. Ethier, M. F., D. E. Wolf, and D. L. Melchior. 1983. Calorimetric investigation of the phase partitioning of the fluorescent carbocyanine probes in phosphatidylcholine bilayers. Biachemistry. 22:1178-1182.

14. Forrester, I. 1980. Effects of digitonin and polymixin B on plasma membrane of ram spermatozoa - an EM studx Arch. Androl. 4:195-204.

15. Friend, D. S. 1977. Organization of the spermatozoal membrane. In Immunobiology of the Gametes. M. Edidin and M. H. Johnson, editors. Alden Press, Cambridge, England. $5-30$.

16. Frye, L. D., and M. Edidin. 1970. The rapid intermixing of cell surface antigens after formation of mouse-human heterokaryons. J. Cell Sci. 7:319-335.

17. Hammersteadt, T. H. 1979. Characterization of sperm surfaces using physical tech niques. In The Spermatozoon. D. W. Fawcett and J. M. Bedford, editors. Uban and Schwarzenberg, Baltimore, MD. 205-218.

18. Horrocks, L. A., and M. Sharma. 1982. Plasmalogens and $O$-alkyl glycerophospholipids In Phospholipids. J. N. Hawthorne and G. B. Ansell, editors. Elsevier/North-Holland Biomedical Press, Amsterdam. $51-93$.

19. Johnson, L. V., M. L. Walsh, and L. B. Chen. 1980. Localization of mitochondria in living cells with thodamine 123. Proc. Natl. Acad. Sci. USA. 77:990-994.

20. Klausner, R. D., A. M. Kleinfeld, R. L. Hoover, and M. J. Kamovsky. 1980 . Lipid domains in membranes: evidence derived from structural perturbations induced by free fatty acids and lifetime heterogeneity analysis. $J$. Biol. Chem. 255:1286-1295.

21. Klausner, R. D., and D. E. Wolf. 1980. Selectivity of fluorescent lipid analogues for lipid domains. Biochemistry. 19:6199-6203.

22. Koehler, J. K. 1978. The mammalian sperm surface: studies with specific labeling techniques. Int. Rev. Cytol. 54:73-108.

23. Koo, G. C., E. A. Boyse, and S. S. Wachtel. 1977. Immunogenetic techniques and approaches in the study of sperm and testicular cell surface antigens. In Immunobiology of Gametes. M. Edidin and M. H. Johnson, editors. Cambridge University Press, Cambridge, England. 73-84.

24. Koppel, D. E. 1979. Fluorescence redistribution after photobleaching: a new multipoin analysis of membrane translational dynamics. Biophys. J. 28:281-292.

25. Koppel, D. E., D. Axelrod, J. Schlessinger, E. L. Elson, and W. W. Webb. 1976 Dynamics of fluorescence marker concentration as a probe of mobility. Biophys. $J$. 16:1315-1329

26. McNutt, N. S., and R. S. Weinstin. 1973. Membrane ultrastructure at mammalian intracellular junctions. Prog. Biophys. Mol. Biol. 26:45-101.

27. Millette, C. F. 1979. Appearance and partitioning of plasma membrane antigens during mouse spermatogenesis. In The Spermatozoon. D. W. Fawcett and J. M. Bedford, editors. Uban and Schwarzenberg, Baltimore, MD. 177-186.

28. Nicholson, G. L., and R. Yanagimachi. 1974. Mobility and the restriction of mobility of plasma membrane lectin-binding components. Science (Wash. DC). 184:1294-1296.

29. Nicolson, G. L., and R. Yanagimachi. 1979. Cell surface changes associated with the epididymal maturation of mammalian spermatozoa. In The Spermatozoon. D. W. Fawcett and J. M. Bedford, editors. Uban and Schwarzenberg, Baltimore, MD. 187194

30. O'Rand, M. G. 1979. Changes in sperm surface properties correlated with capacitation In The Spermatozoon. D. W. Fawcett and J. M. Bedford, editors. Uban and Schwarzenberg, Baltimore, MD. 195-204.

31. Pessin, J. E., and M. Glaser. 1980. Budding of Rous sarcoma virus and vesicular stomatitis virus from localized lipid regions in the plasma membrane of chicken embryo fibroblasts. J. Biol. Chem. 255:9044-9050.

32. Peters, R. 1981. Translation diffusion in the plasma membrane of single cells as studied by fluorescence microphotolysis. Cell Biol. Int. Rep. 5:733-760.

33. Portis, A., C. Newton, W. Pangborn, and D. Papahadjopoulos. 1979. Studies on the mechanism of membrane fusion-evidence for an intermembrane $\mathrm{Ca}^{++}$-phospholipid complex, synergism with $\mathrm{Mg}^{+}$, and inhibition by spectrin. Biochemistry. 18:780-790.

34. Pringle, M. J., and K. W. Miller. 1981. Differential effects on phospholipid phase transitions produced by structurally related longchain alcohols. Biochemistry 18:3314 3320

35. Quinn, P. J., and I. G. White. 1967. Phospholipid and cholesterol content of epididymal and ejaculated ram spermatozoa and seminal plasma in relation to cold shock. Aust. $J$ Biol. Sci. 20:1205-1215.

36. Schlegel, R. A., B. M. Phelps, A. Waggoner, L. Terada, and P. Williamson. 1980 Binding of merocyanine 540 to normal and leukemic erythroid cells. Cell. 20:321-328.

37. Schmell, E. D., B. J. Gulyas, L. C. Yvan, and J. T. August. Identification of mammalian sperm surface antigens. II. Characterization of an acrosomal cap protein and a tail protein using monoclonal anti-mouse sperm antibodies. J. Reprod Immunol 4:91-106.

38. Schmell, E D. L C. Yuan, B. J Gulyas, and J. T A ugust 1982 Identification of mammalian sperm surface antigens. I. Production of monoclonal anti-mouse sperm antibodies. Fertil. Steril. 37:249-257.

39. Schneider, M. B., and W. W. Webb. 1981. Measurement of submicron laser-beam radii Appl. Opt. 20:1382-1388.

40. Scott, T. W., J. K. Vogimayr, and B. P. Setchell. 1967. Lipid composition and metabolism in testicular and ejaculated ram spermatozoa. Biochem. J. 102:456-461.

41. Shimshick, E. J., and H. M. McConnell. 1973. Lateral phase separation in phospholipid membranes. Biochemistry. 12:2351-2360.

42. Sims, P. J., A. S. Waggoner, C.-H. Wang, and J. F. Hoffman. 1974. Studies on the mechanism by which cyanine dyes measure membrane potential in red blood cells and phosphatidylcholine vesicles. Biochemistry. 13:3315-3330.

43. Singer, S. J., and G. L. Nicolson. 1972. The fluid mosaic model of the structure of cell membranes. Science (Wash. DC). 175:720-731.

44. Sklar, L. A., G. P. Miljanich, and E. A. Dratz. 1979. Phospholipid lateral phase separation and the partition of cis-parinaric acid and trans-parinaric acid among aqueous solid lipid and fluid lipid phases. Biochemistry. 18:1707-1716.

45. Straehlin. L. A. 1974. Structure and function of intercellular junctions. Int. Rev. Cytol. 39:191-283

46. Tank, D. W., E.-S. Wu, and W. W. Webb. 1982. Enhanced molecular diffusibility in muscle membrane blebs: release of lateral constraints. J. Cell Biol. 92:207-212.

47. Tung, K. S. K. 1977. The nature of antigens and pathogenetic mechanisms in autoimmunity to sperm. In Immunobiology of Gametes. M. Edidin and M. H. Johnson, editors., Cambridge University Press, Cambridge, England. 157-185.

48. Voglmayr, J, K., G. Fairbanks, D, B. Vespa, and J. R. Colella. 1982. Studies on mechanisms of surface modifications in ram spermatozoa during the final stages of differentiation. Biol. Reprod. 26:483-500.

49. Voglmayr, J. K., N. A. Musto, S. K. Saksena, P. D. C. Brown-Woodman, P. B. Marley, and I. G. White. 1977. Characteristics of semen collected from the cauda epididymidis of conscious rams. J. Reprod. Fertil. 49:245-251.

50. Voglmayr, J. K., T. W. Scott, B. P. Setchell, and G. M. H. Waites. 1967. Metabolism of testicular spermatozoa and characteristics of testicular fluid collected from conscious rams. I. Reprod Fertil. 14:87-99.

51. Wolf, D. E., and M. Edidin. 1981. Methods of measuring diffusion and mobility of molecules in surface membranes. In Techniques in Cellular Physiology. P. Baker, editor Elsevier/North-Holland Biomedical Press, Amsterdam. P1/1, 105:1-14.

52. Wolf, D. E., M. Edidin, and A.H. Handyside. 1981. Changes in the organization of the mouse egg plasma membrane upon fertilization and first cleavage: indications from the lateral diffusion rates of fluorescent lipid analogs. Dev. Biol. 85:195-198.

53. Wolf, D. E., W. Kinsey, W. Lennarz, and M. Edidin. 1981. Changes in the organization of the sea urchin egg plasma membrane upon fertilization: indications from the lateral diffusion rates of lipid-soluble fluorescent dyes. Dev. Biol. 81:133-138.

54. Wolf, D. E. and C. A. Ziomek. 1983. Regionalization and lateral diffusion of membrane proteins in unfertilized and fertilized mouse eggs. J. Cell Biol. 96:1786-1790.

55. Wu, E.-S., D. W. Tank, and W. W. Webb. 1982. Unconstrained lateral diffusion of concanavalin A receptors of bulbous lymphocytes. Proc. Natl. Acad. Sci. USA. 79:4962 4966 